\title{
Interdisciplinary Interation in Design - Relation Between Graphic and Interior Design
}

\author{
Rana Kutlu \\ Department of Interior Architecture and Environmental Design, Istanbul Kültür University, Istanbul, Turkey
}

Email address:

r.kutlu@iku.edu.tr

\section{To cite this article:}

Rana Kutlu. Interdisciplinary Interation in Design - Relation Between Graphic and Interior Design. International Journal of Science, Technology and Society. Vol. 4, No. 1, 2016, pp. 14-20. doi: 10.11648/j.ijsts.20160401.13

\begin{abstract}
Nowadays the concept of "identity" is worked on diligently as a marketing strategy and deemed as an important tool in concept works of design disciplines of different scales through physical space, which reaches out to consumers. In this study, through the literature review, impacts of identity on spatial design are discussed in terms of interdisciplinary communication and tools used for transferring the meaning, which transforms identity into image are listed. Besides, the impact of spatial design on users' perception is explained in connection with graphic design, architecture and interior architecture. Tools used for meaning transfer, which play a role in defining and developing design based on identity, are evaluated together with identity and image creating processes.
\end{abstract}

Keywords: Space, Graphic Design, Interdisciplinary Interaction, Relevance to Design Practice

\section{Introduction}

Design has continuously been evolving and developing under the influence of art movements and in the light of experience and technical and material-related developments throughout the history. Understanding and perception of design have resulted in changes in forms and their meanings (Bielefeld, Khouli 2010) The issue of defining brandingidentity has come to prominence in a wide variety of fields from individual products to service industry as a result of increasing competition and globalization seen in design, as well, just like anywhere else. As expressed by Baudrillard (2002), the fact that the identity message given by the product has taken precedence over its value of use shows that nowadays its meaning is more important than the product itself. In this regard, designers have adopted a multidisciplinary approach and started to work with not only engineers but also with teams comprising of representatives of various professions like artists, graphic designers, communication experts and to achieve a versatility in design thanks to interdisciplinary communication.

We observe a close link between architecture and art following the Industrial Revolution in De Stijl approach and in Bauhaus movement, where various and versatile art branches like sculpture, handicraft and painting can be found together. (Fielden, Geoffrey, 1963). Besides, nesting of architectural design and art brings along conceptual integrity pursuant to spatial identity. Graphic design has played an important role in actualizing this conceptual integrity in terms of deepening meaning of the space, providing information transfer and creating an identity for the space. Especially in recent years graphic design has gone beyond advertising displays and billboards and become an influential discipline with regards to giving architecture and environment an identity through information transfer in environmental and spatial design.

\section{Graphic Design and Historical Development}

Any quality defining the entity and making it different from others of the same kind forms identity. Identity is the way an entity expresses itself. Image comes into being when identity is shaped in others' memory and perception (Dewey, J., 1997).

Graphic design is one of the most important disciplines and arts providing visual communication. It is also a visual tool, which provides the users with information and message esthetically and cutting extra corners. Designers use space to give a message in architecture. In line with this objective, architecture, which is discussed in different scales in physical environment designed for the user, will bear its fruits in cooperation with interior architecture, industrial design and 
graphic design.

Cave drawings dating back from ancient times to upper Paleolithic era and to 14000 's B. C. can be deemed as the first graphic works of human beings, in which they use art as a way of communication. As a result of development of modern life following the Industrialization, invention of photography, establishment of printing press, products like graphic, catalogue or posters were first started to be designed by painters. For this reason, pictorial aspects were put first rather than typographic features. Thanks to printing techniques developed in time, graphic design has become a separate discipline.

Graphic design has been set apart from painting art towards the end of the 18th century thanks through book designs. It continued to develop rapidly especially pursuant to innovations brought by the Bauhaus School through reactive approaches to art and design. Later on, efforts to give space an identity through image and perception based design have gained momentum in order to create attraction, popularity, awareness and privilege even in building typologies having different functions than retail industry under the influence of semiotics which can be found in conceptual infrastructure of PostModern culture. In this period, graphic expressions that communicate with symbols in contrast to simplicity of the modern architecture have become more important in both architectıre and environmental design.

Designers like Venturi, who have adopted Post Modernism and symbolic architecture, consider architecture to be the main system reaching out to the society. It is possible to increase diversity by combining different functions to strengthen the transfer of message in spaces under design and thereby to achieve an identity transfer. To this end, brandidentity-image works, which count as subjects of graphic design, have gained significance in architectural design. Spatial meaning can be transferred by symbol, photo, collage, illustration, pictogram and typography works.

Visual perception is of crucial importance in graphic design, which transfers meaning via materials and technology developed in recent years in construction industry. Uses and options of graphic design are diversified beyond the ordinary thanks to digital technology and interactive surfaces, which are also motion/user/environment sensitive, smart glass technologies with different levels of transparency, LED that gives wide range of opportunities especially in illumination and last but not least OLED technologies which are still developing.

\section{The Relation Between Visual Perception - Spatial Design - Graphic Design}

Architecture consists not only of eyesight since the visual difference which can be perceived by the user can be achieved by design, but it also involves other senses. It is also a tool that links us with space and time. (Pallasmaa, 2005), (Anderson, J., 2011). Architects often employ design methods to help them find more creative forms. These methods make it possible to break free of the traditional canon of forms and established paradigms (Jormakka, 2008) The desire for designing and creating space is a way of communication for human beings using objects, materials, colors and forms rather than verbal tools(Brooker, Stone, 2010). Message carried by the space can be transferred to users via an interdisciplinary cooperation using tangible, abstract, audio, visual aspects (Pallasmaa, 2009). Interdisciplinary relation in transfer of identity related meaning in design can be seen in Figure 1.

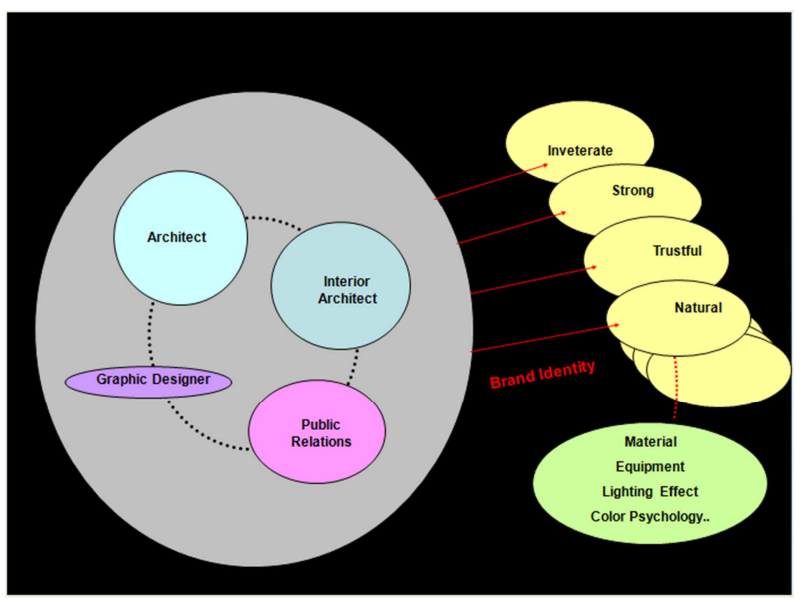

Figure 1. Interdisciplinary relation in transferring identity related meaning in design.

Humans receive sensory data that form perception through stimuli in outer environment. Visual sense is faster than auditory, smell and tactile senses in terms of perceiving natural and artificial environment. Transfer of the identityrelated message through visual communication established between the space and the user and solution options in line with spatial functions can be achieved easily thanks to graphic design. This way, the completed design does not only have functionality but also differentiation through artistic identity given to the space and visual richness.

Visual perception varies person to person. Psychosocial and cultural characteristics and experience play an active role in perception of the message, which is planned to be transferred by the design. Surfaces defining limits of the volume play an important role in graphic design of the space, forming a visual identity, creating a difference and achieving message transfer. These surfaces composing the shell of the space are walls, horizontal planes and floors. Besides, vertical circulation instruments connecting different planes and reinforcement elements of the space are other architectural elements that play a role in visual identity.

According to Faulkner, walls are surfaces which create volumes in volume through their division function as per the relation between spatial and graphic design and it is also where spatial graphic is mostly used. Walls can be opaque, transparent, semi-transparent or variable transparent depending on materials used. They play an active role in describing the space with expressions like privacy-openness, transparency-closeness, dividedness or unity (Figure 2). 


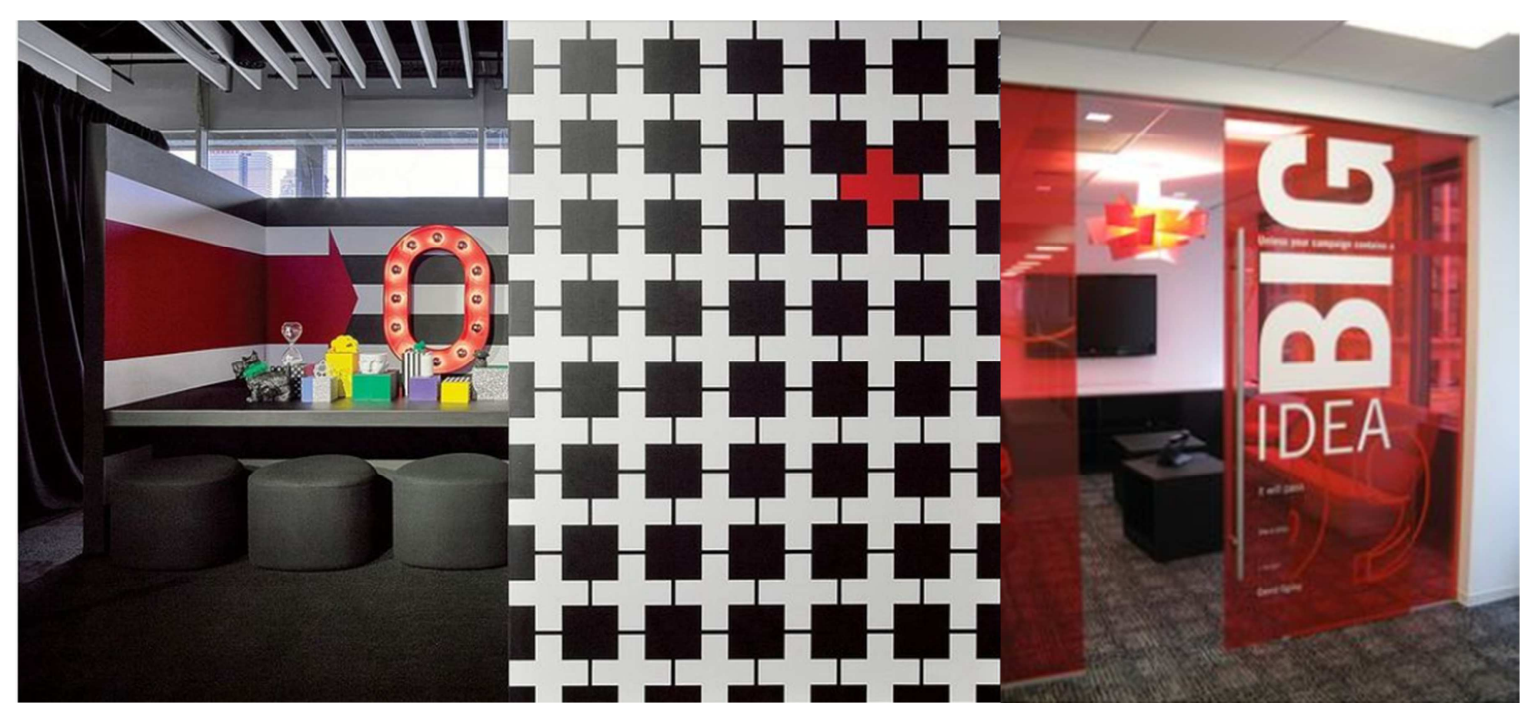

Figure 2. Graphic Design on a Wall Plane (URL-1<http://www.interiordesign.net. Date accessed: 15.06.2015).

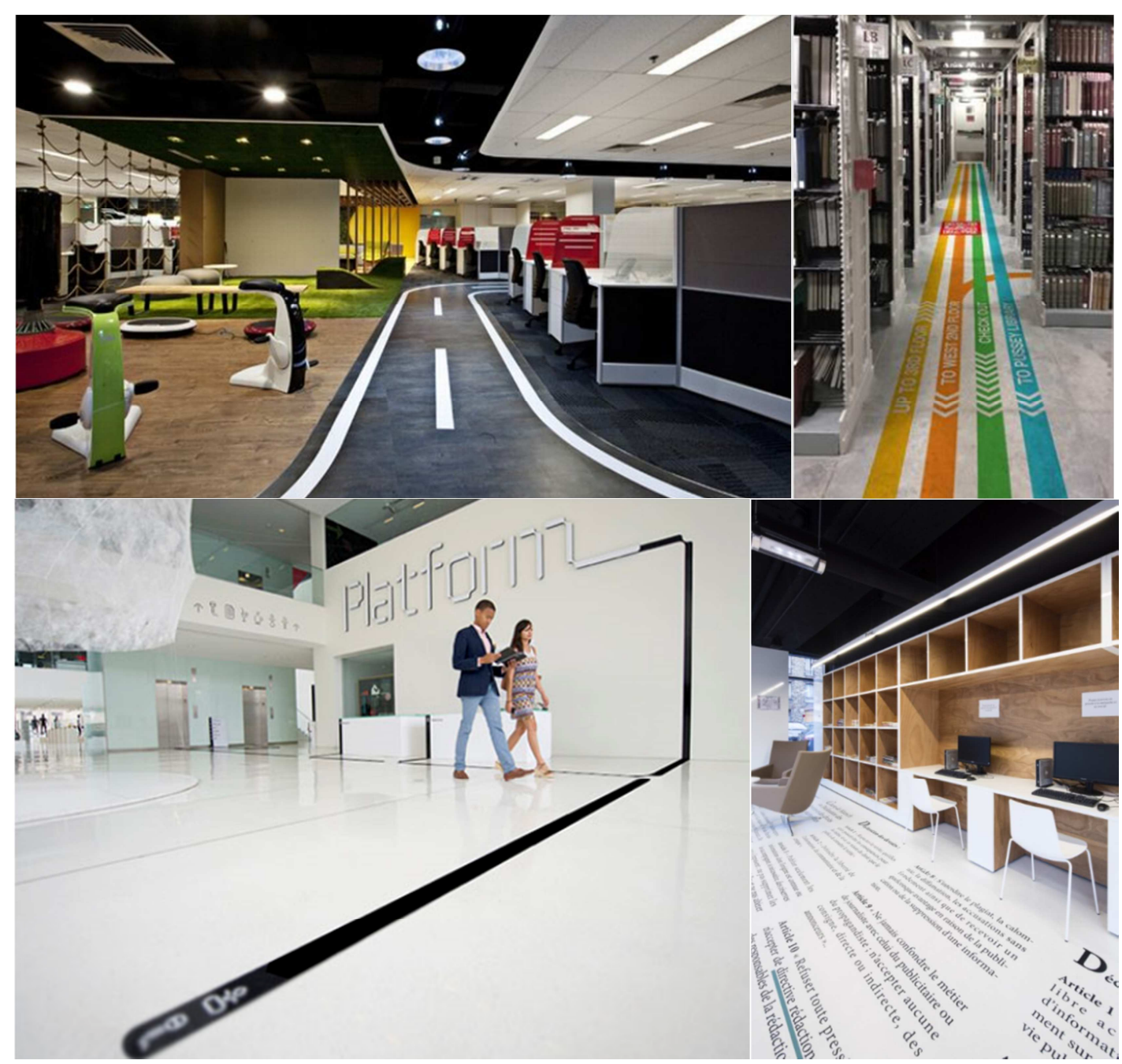

Figure 3. Graphic Design on Covering - Floor Plane (URL-2<http://librarytestkitchen.org, Date accessed: 15.06.2015).

For integrity in design vertical place surface characteristics have to be taken into consideration during the graphic design process. Doors and windows are vertical surfaces pieces that open into the space, thus these are the first building components, which transfer messages via graphic design, stylistic design and construction technique based on the 
atmosphere of the inner space. Whether these components are opaque, transparent, semi-transparent, wooden, metal or plastic determines graphic design of how message is to be transferred. Functions which are to be added to vertical planes like exhibitions, information boards/ panels or planes to be used for storing purposes have to be in line with the architectural design integrity not only for graphic design but also as for the technology and materials to be used.

Covering and floors are surfaces used intensively in effective spatial graphic for continuity, flow and guidance in differentiating between different materials or elevation, which are in close contact with users like walls. Graphic prints on the floor can be partially extended to the walls or even to the ceiling having a restrictive or guiding impact as can be seen in Figures 3 and 4.The ceiling, upper horizontal plane bordering the volume, is another important architectural element which completes inner space, closes on the third dimension, doesn't directly contact the user in contrast to walls and floors, is located further away. Humans' field of vision covers an angle of $40^{\circ}$ on horizontal and vertical axis and thus architectural elements like floor, wall and ceiling are surfaces, which have an impact on design and can be used for guidance; and where graphic design can be used effectively to create the defined identity-related image (Figure 4).

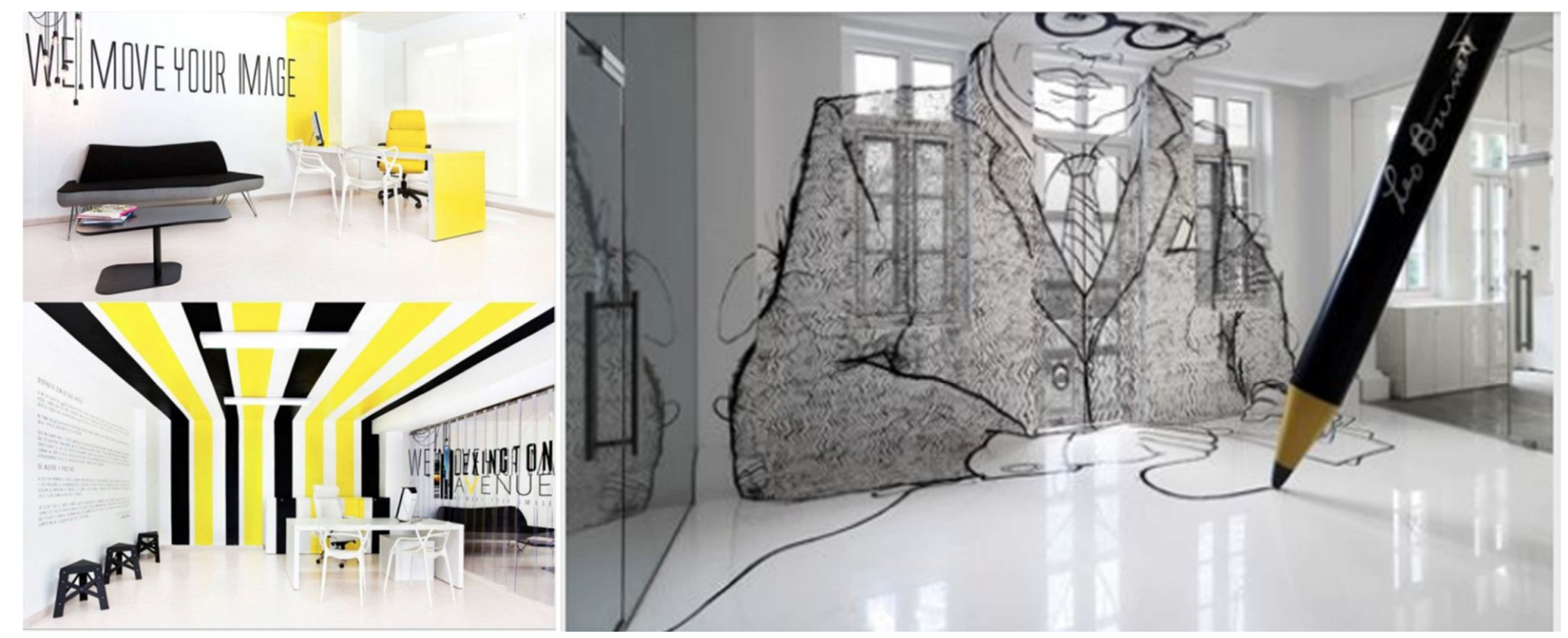

Figure 4. Graphic Design in Floor-Ceiling Plane (URL-3<http:// asphaltartusa.com, Date accessed: 15.06.2015).

Vertical circulation instruments like stair, ramp and elevator first of all serve for continuity and guidance between elevation and floors and can also be used as surface for graphic design the emphasize the abovementioned purposes.

Vertical circulation instuments are not only functional but they can also be art objects adding esthetic features to the building thanks to their forms, colors and material compositions. Message/information transfer on different vertical circulation elements like stairs, elevators and escalators can be seen in Figure 5.
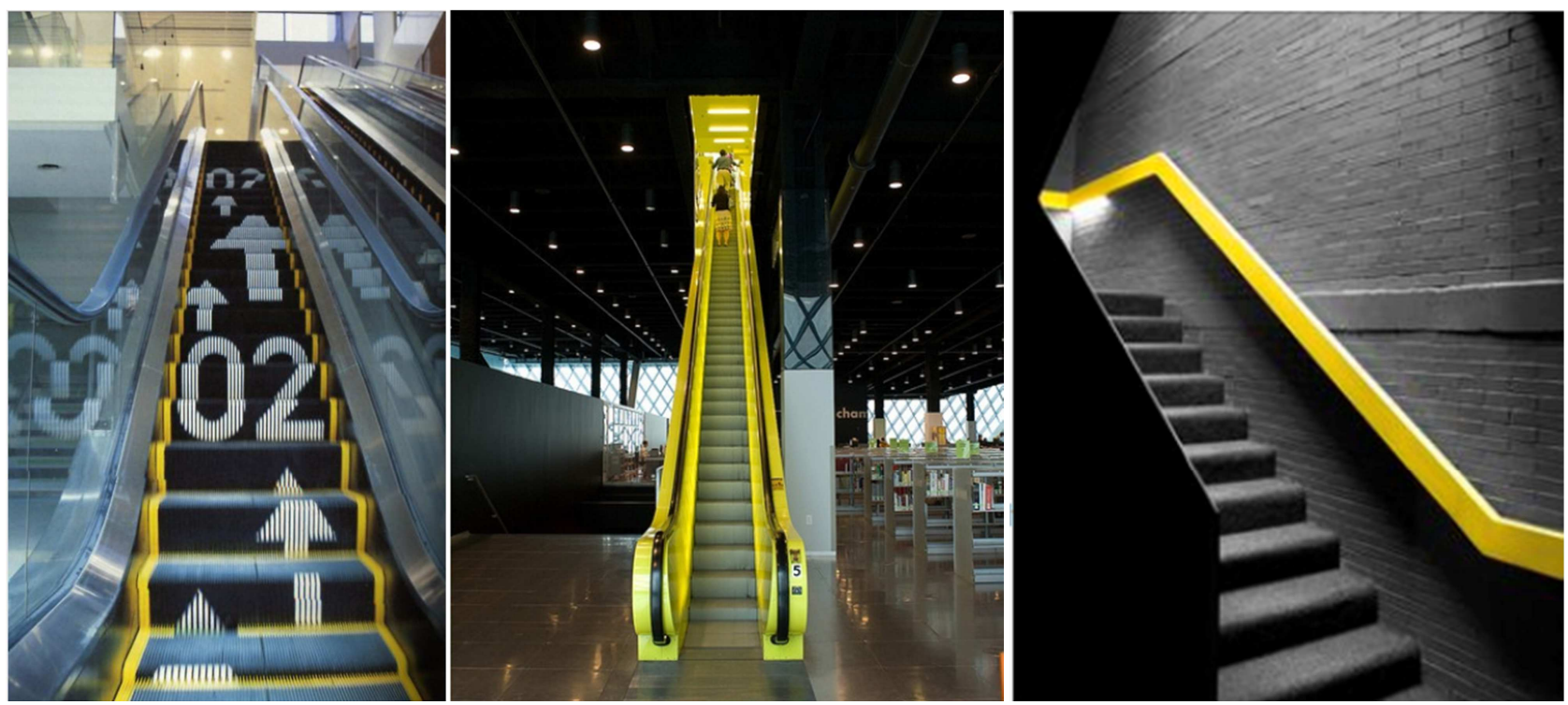


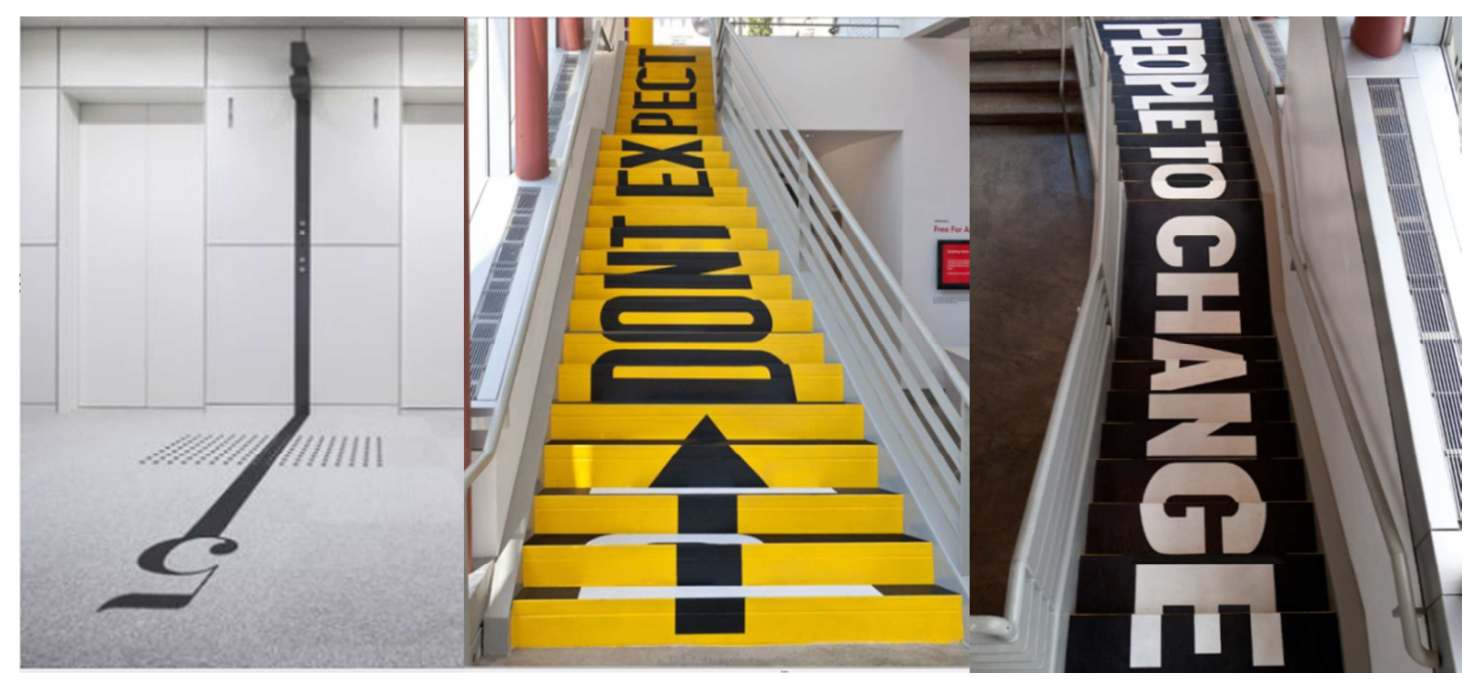

Figure 5. Vertical Circulation - Graphic Design (URL-4<http://www.flicker.com, Date accessed: 15.06.2015).
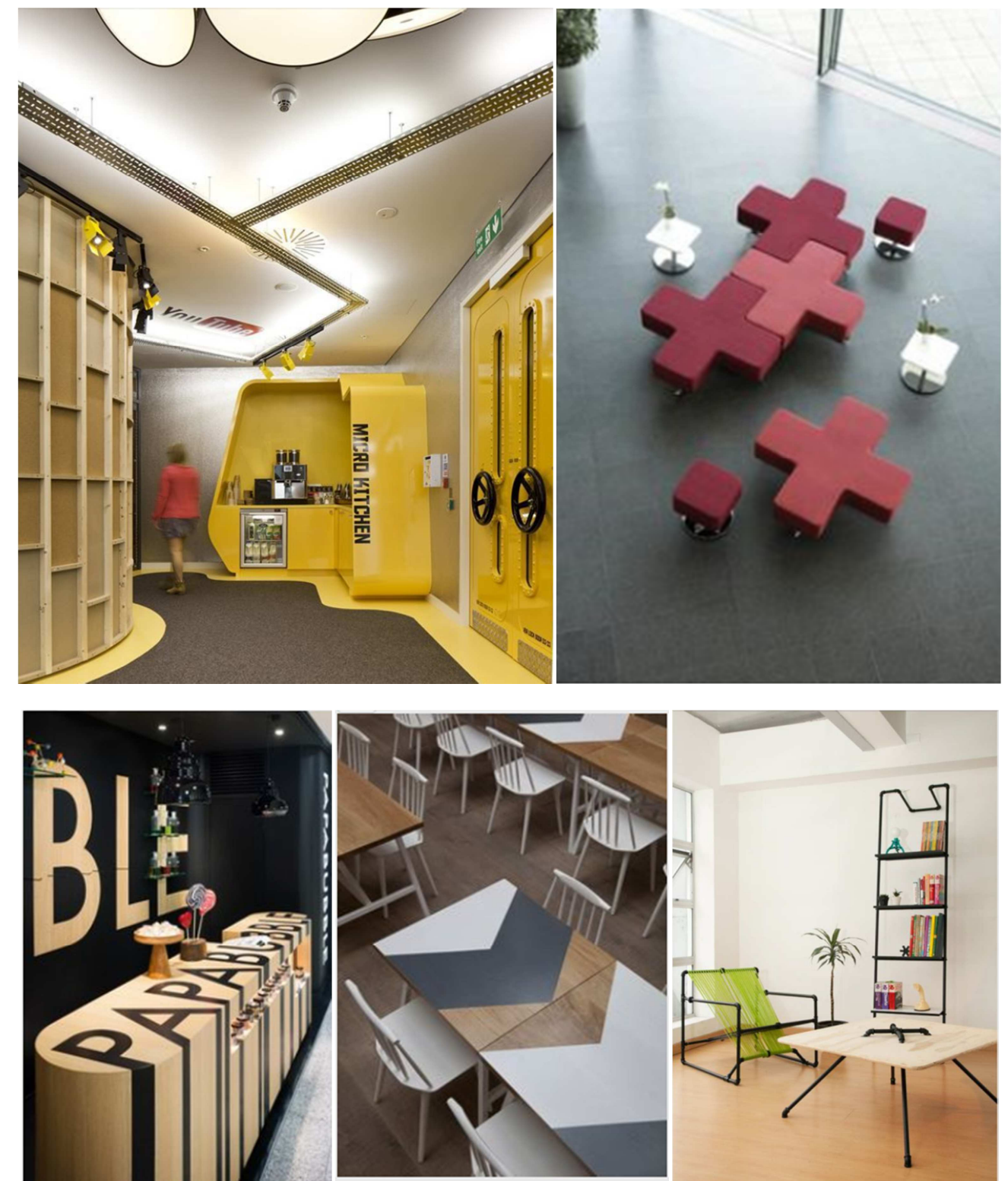

Figure 6. Reinforcement Elements - Graphic Design (URL-5<http://www.officefurniturescene.co.uk, Date accessed: 15.06.2015). 
Reinforcement elements can be fixed or moving, horizontal/vertical/inclined in the field of view, at low or high levels. Reinforcements elements, which are designed, and colored, given texture and equipped with materials in line with the spatial design and identity, play an active role in forming a message which matches the identity in the memory of the user in terms of graphic design in addition to fulfilling main design principles like background-object contrast or harmony, rhythm, continuity, consistency, diversity in unity, balance and emphasis (Figure 6).

Visual images like photos, illustration, typography and pictogram, which would emphasize the desired message and space identity defined by the designer on all planes and reinforcement elements composing the space and spatial graphic design compositions which are formed with visual images shall be meticulously discussed in terms of achieving both functional and successful visual communication.

Following adaptation of rapidly developing technology into architectural elements as meaning transfer tools, the relation between architecture and graphic design has gained a new dimension and adapted itself to the new order. Variations of the relation between architectural elements, which will transfer the identity related message through graphic design tools can be seen Figure 7.

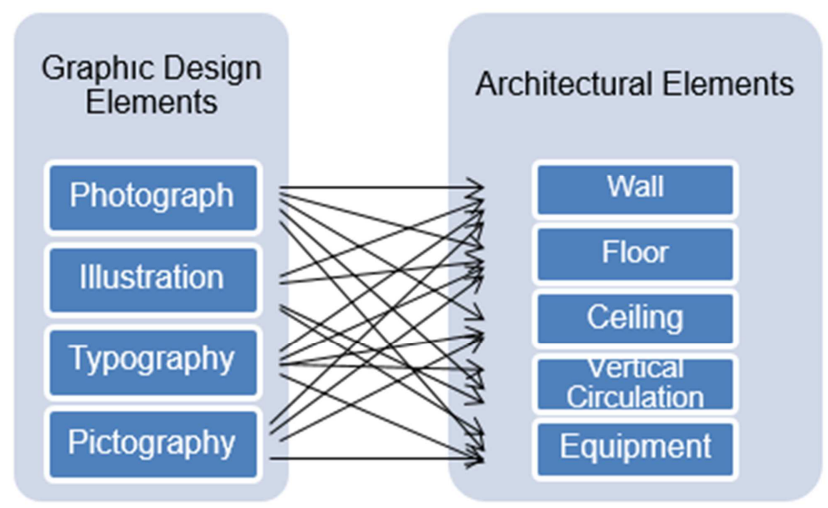

Figure 7. The Relation Between Spatial Meaning Transfer Tools and Graphic Design.

Fixed print or mobile digital arrangements can be done on two dimensional planes using a photograph with high resolution, enough light and a strong graphic language which is used in spatial design to influence visual perception.

Another example for graphic works that is used effectively to give a space an identity is illustrations. Illustration is a common artistic way of expression, which can be understood by everyone independently of language and culture. It is also one of the strong esthetic links strengthening the relation between the space and users.

Typographies, which shapes volume with letters and lines can be either two or three dimensional. They occupy an important position among other graphic design elements in transfer of identity of the space.

Pictogram is defined as international symbol representing a concept, object or a function. It is composed of graphic drawings and is a strong tool for message transfer. It has esthetic and functional aspects within the space gaining three dimensions in the volume or on two dimensional planes as a strong graphic design tool in identity based message transfer in creating the planned image in the memory of the user. Various graphic design works on architectural elements such as photo, illustration, typography and pictogram can be seen in Figure 8.
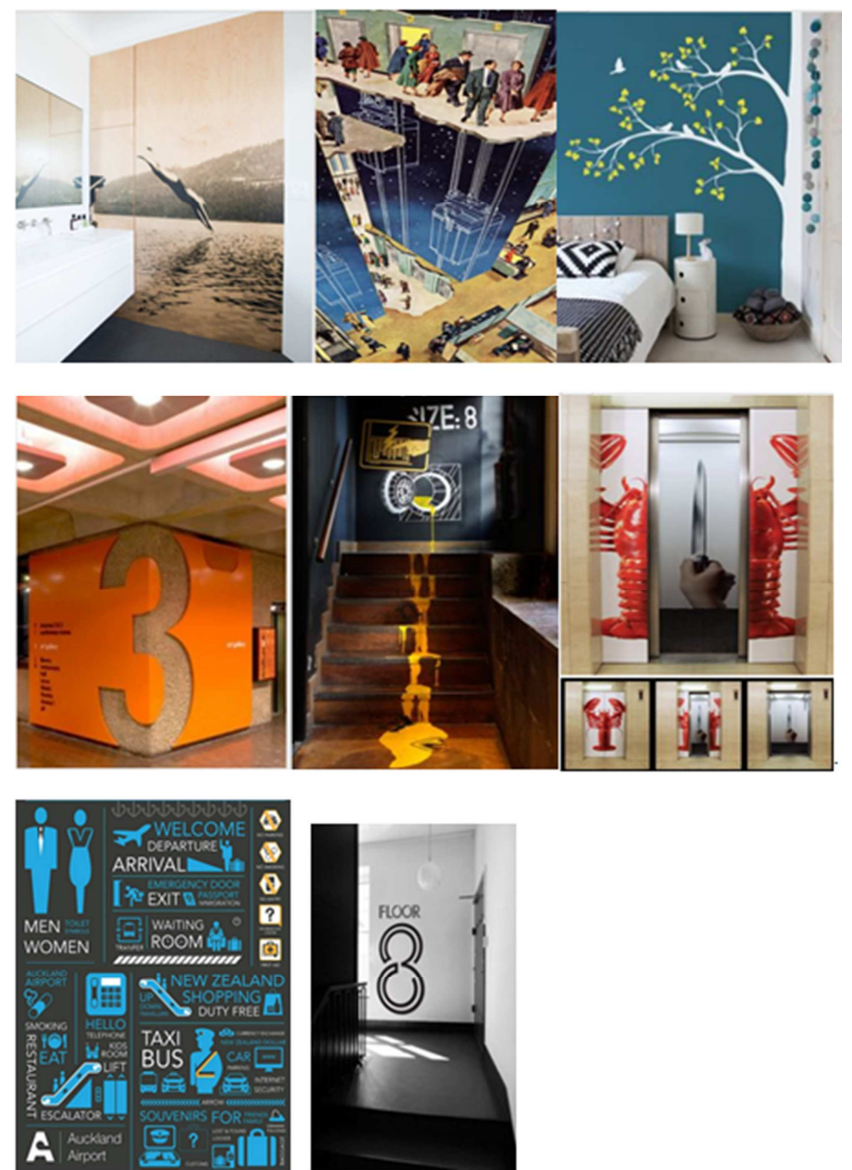

Figure 8. Graphic Design Tools- Photo-Illustration-Typography-Pictogram (URL-6<http://www.design-milk.com, Date accessed: 15.06.2015).

\section{Conclusion}

Nowadays we see that successful designs are open to multidisciplinary approaches and works. Architecture, which is a place for interaction and experience, is not only a useful artistic production with its functional, esthetic and design features but also a physical environment and a living space where corporate identity works are transferred to the user through this space.

Life of space lasts longer than lives of actions and users involved. Although physical existence of spaces, which have had different functions throughout time and served different groups of users remain the same, the messages it carries or the communication it establishes change in time. Since experience offered by the space directly affects the image, it is one of the most important meaning transfer tools. It covers 
various design decisions and a wide range of issues like the relation between location of the space and outer environment, details regarding reinforcement elements of inner space, color and illumination designs and graphic expressions. The concept, on which all of these design decisions depend, expresses the overall identity.

The relation between architecture and graphic design should be discussed with a holistic approach in reflecting the corporate identity on the space forming a visual perception. Supporting this interdisciplinary cooperation will have a positive impact on giving the space an identity. Interdisciplinary design approaches have generally proven to bear successful results throughout the history.

Interdisciplinary interaction will make it easier for a designer to reflect his/her talents and authenticity on the space with a broader point of view; nourish the design process and offer chances of new experience through spatial communication.

\section{References}

[1] Anderson, J., (2011), Basics Architecture, Architectural Design 03 AVA Publishing SA, Switzerland.

[2] Baudrillard, J., (2004), The Consumer Society, Myths and Structures, Sage Publications, London.

[3] Baudrillard, J., (2012), Tüketimin Tanımına Doğru, Mimarlık ve Tüketim, Boyut Yayınları, İstanbul, s: 67-72.
[4] Bielefeld, B. \& Khouli, S. El, (2010), Basics Entwerfen Entwurfsidee, Birkäuser.

[5] Brooker, G., Stone, S., (2010), What Is Interior Design? Essential Design Hanbooks, Roto Vision SA, Switzerland.

[6] Dewey, J., (1997), How We Think. USA: Dover Publication.

[7] Fielden, Geoffrey BR. et. al., (1963), Engineering Design. London: HMSO.

[8] Faulkner, R. (1979). Planning a Home. Holt, Rinehartand Winston, New York.

[9] Jormakka, K., (2008), Design Methods, Birkäuser.

[10] Pallasmaa, J., (2005), The Eyes of the Skin: Architecture and Senses, Wiley, Chichester.

[11] Pallasmaa, J. (2009). The Thinking Hand Existential and Embodied Wisdom in Architecture. West Sussex, UK: John Wiley \& Sons Ltd.

[12] URL-1<http://www.interiordesign.net. Page accessed: 15.06.2015.

[13] URL-2<http://librarytestkitchen.org, Page accessed: 15.06.2015.

[14] URL-3<http:// asphaltartusa.com, Page accessed: 15.06.2015.

[15] URL-4<http://www.flicker.com, Page accessed: 15.06.2015.

[16] URL-5<http://www.officefurniturescene.co.uk, Page accessed: 15.06.2015.

[17] URL-6<http://www.design-milk.com, Page accessed: 15.06.2015. 